University of Nebraska - Lincoln

DigitalCommons@University of Nebraska - Lincoln

10-2011

\title{
Picotesla Magnetic Sensors for Low-Frequency Applications
}

\author{
Sy-Hwang Liou \\ University of Nebraska-Lincoln, sliou@unl.edu \\ Xiaolu Yin \\ University of Nebraska-Lincoln \\ Stephen Russek \\ National Institute of Standards and Technology, stephen.russek@nist.gov \\ Ranko Heindl \\ National Institute of Standards and Technology, heindl@boulder.nist.gov \\ F. C. S. Da Silva \\ National Institute of Standards and Technology, fabio.dasilva@nist.gov \\ See next page for additional authors
}

Follow this and additional works at: https://digitalcommons.unl.edu/physicsliou

Part of the Physics Commons

Liou, Sy-Hwang; Yin, Xiaolu; Russek, Stephen; Heindl, Ranko; Da Silva, F. C. S.; Moreland, J.; Pappas, David P.; Yuan, L.; and Shen, J., "Picotesla Magnetic Sensors for Low-Frequency Applications" (2011). Si-Hwang Liou Publications. 100.

https://digitalcommons.unl.edu/physicsliou/100

This Article is brought to you for free and open access by the Research Papers in Physics and Astronomy at DigitalCommons@University of Nebraska - Lincoln. It has been accepted for inclusion in Si-Hwang Liou Publications by an authorized administrator of DigitalCommons@University of Nebraska - Lincoln. 


\section{Authors}

Sy-Hwang Liou, Xiaolu Yin, Stephen Russek, Ranko Heindl, F. C. S. Da Silva, J. Moreland, David P. Pappas, L. Yuan, and J. Shen 


\title{
Picotesla Magnetic Sensors for Low-Frequency Applications
}

\author{
S. H. Liou ${ }^{1}$, Xiaolu Yin ${ }^{1}$, Stephen E. Russek ${ }^{2}$, Ranko Heindl ${ }^{2}$, F. C. S. Da Silva ${ }^{2}$, John Moreland ${ }^{2}$, \\ David P. Pappas ${ }^{2}$, L. Yuan ${ }^{3}$, and J. Shen ${ }^{3}$ \\ ${ }^{1}$ Department of Physics and Astronomy and Nebraska Center for Materials and Nanoscience,University of Nebraska, Lincoln, \\ NE 68588-0111 USA \\ ${ }^{2}$ National Institute of Standards and Technology, Boulder, CO 80305 USA \\ ${ }^{3}$ Western Digital Corporation, Fremont, CA 94539 USA
}

\begin{abstract}
We demonstrate a simple low-power, magnetic sensor system suitable for high-sensitivity magnetic-field mapping, based on solid-state magnetic tunnel junction devices with minimum detectable fields in a $100 \mathrm{pT}$ range at room temperature. In this paper, we discuss a method that uses multilayer thin films to improve the performance of the soft ferromagnetic layer in magnetoresistive sensor applications, by reducing the coercivity and/or improving the reversibility. We have used it in the design of our new magnetic sensor. This sensor has a sensitivity as high as $750 \% / \mathrm{mT}$. The magnetic sensor only dissipates $1 \mathrm{~mW}$ of power while operating under an applied voltage of $1 \mathrm{~V}$.
\end{abstract}

Index Terms-Magnetic concentrators, magnetic noise, magnetic sensor, magnetic tunnel junction (MTJ).

\section{INTRODUCTION}

$\mathbf{T}$ HE measurement of magnetic field in the picotesla range is important for a wide range of homeland security, industrial, and biomedical applications. Many of these applications require sensors with field noise of less than $1 \mathrm{nT} / \mathrm{Hz}^{1 / 2}$, as well as low-frequency operation, low maintenance, and low power consumption [1]-[12].

The minimum detectable field (the field noise times the measurement bandwidth) of magnetic tunnel junction (MTJ) sensors is limited by thermal Johnson, shot, electronics, and magnetic noise, in which magnetic noise dominates at low frequencies and nonreversible (hysteretic) behavior, current state-of-the-art MTJ devices have not demonstrated the desired performance.

In this paper, we discuss a method that uses multilayer thin films to improve the performance of the soft ferromagnetic layer in magnetoresistive (MR) sensor applications, by reducing the coercivity and/or improving the reversibility. In this study, a layer of very soft $\mathrm{Fe}_{20} \mathrm{Ni}_{80}$ is added onto the $\mathrm{Co}_{20} \mathrm{Fe}_{60} \mathrm{~B}_{20}$ transition-metal layers that show a moderate improvement of the soft-magnetic performance. We demonstrate a simple low-power, magnetic sensor system suitable for high-sensitivity magnetic field mapping, based on solid-state MTJ devices with minimum detectable fields in the picotesla range at room temperature. The key features of this design are: 1) decreasing the noise by the use of a 64-element MTJ bridge, 2) reducing the magnetic hysteresis by using a coupled soft magnetic layer, and 3 ) increasing the signal by using an external flux-to-field magnetic flux concentrators (MFCs). This sensor has a sensitivity as high as $750 \% / \mathrm{mT}$. The magnetic sensor only dissipates $1 \mathrm{~mW}$ of power, while operating under a applied voltage of $1 \mathrm{~V}$.

Manuscript received February 22, 2011; revised May 14, 2011, May 15, 2011 ; accepted May 15, 2011. Date of current version September 23, 2011. Corresponding author: S.-H. Liou (e-mail: sliou@unl.edu).

Color versions of one or more of the figures in this paper are available online at http://ieeexplore.ieee.org.

Digital Object Identifier 10.1109/TMAG.2011.2157997

\section{EXPERIMENTAL DeTAILS}

We have used two types of MTJ layer structures for this study. The MTJ layer structure for the ferromagnetic-ferromagnetic coupling study (MTJ-A) is $1.5 \mathrm{~nm} \mathrm{Ta} / 15 \mathrm{~nm}$ $\mathrm{Ru} / 3 \mathrm{~nm} \mathrm{Co}{ }_{40} \mathrm{Fe}_{60} / 10 \mathrm{~nm} \mathrm{Ir}_{20} \mathrm{Mn}_{80} / 2.2 \mathrm{~nm} \mathrm{Co}_{40} \mathrm{Fe}_{60} / 0.85 \mathrm{~nm}$ $\mathrm{Ru} / 2.8 \mathrm{~nm} \mathrm{Co}{ }_{20} \mathrm{Fe}_{60} \mathrm{~B}_{20} / 2 \mathrm{~nm} \mathrm{MgO} / 4 \mathrm{~nm} \mathrm{Co}_{20} \mathrm{Fe}_{60} \mathrm{~B}_{20} / 10 \mathrm{~nm}$ $\mathrm{Ta} / 7 \mathrm{~nm} \mathrm{Ru}$. The MTJ layer structure for the sensor (MTJ-B) is $1.5 \mathrm{~nm} \mathrm{Ta} / 25 \mathrm{~nm} \mathrm{Ru} / 7 \mathrm{~nm} \mathrm{Ir}_{20} \mathrm{Mn}_{80} / 2.2 \mathrm{~nm}$ $\mathrm{Co}_{40} \mathrm{Fe}_{60} / 0.85 \mathrm{~nm} \mathrm{Ru} / 2.8 \mathrm{~nm} \mathrm{Co}_{20} \mathrm{Fe}_{60} \mathrm{~B}_{20} / 2 \mathrm{~nm} \mathrm{MgO} / 1.5 \mathrm{~nm}$ $\mathrm{Co}_{20} \mathrm{Fe}_{60} \mathrm{~B}_{20} / 3.3 \mathrm{~nm} \mathrm{Ni}{ }_{80} \mathrm{Fe}_{20} / 1 \mathrm{~nm} \mathrm{Ta} / 15 \mathrm{~nm} \mathrm{Ru}$.

The junctions were patterned into ellipses with a size of $10 \mu \mathrm{m} \times 15 \mu \mathrm{m}$ (area $117.8 \mu \mathrm{m}^{2}$, eccentricity 0.74 ) and a circle $30 \mu \mathrm{m} \times 30 \mu \mathrm{m}$ (area $706.9 \mu \mathrm{m}^{2}$ ) by photolithography and argon milling. The MTJ sensor bridge was annealed at $350{ }^{\circ} \mathrm{C}$ under a $1 \mathrm{~T}$ magnetic field for $30 \mathrm{~min}$ and a vacuum of $1.33 \times 10^{-5} \mathrm{~Pa}$. The pinning direction of the reference layer is along the short axis of the ellipse. It has been reported early that the magnetic sensor noise will increase the SNR by $\sqrt{N}$, where $N$ is the number of MTJ elements either in series or parallel [13]. So, we have designed our magnetic sensor with a 64-element bridge for reducing the noise. The design of the magnetic sensor with a 64-element bridge is the same as that in [14]. The noise measurement system is in a shielded environment to avoid picking up unwanted external magnetic-field fluctuations. The magnetic sensor used in this study was made using an asymmetric bridge (formed by taking two dies and rotating them so that the pinned directions were opposite to each other). The sensor voltage and preamplifier bias are supplied by batteries to minimize noise. The MFC was made using a Conetic alloy, which was annealed under hydrogen environment at $1150{ }^{\circ} \mathrm{C}$ for $20 \mathrm{~h}$ with the cooling rate of about $1{ }^{\circ} \mathrm{C} / \mathrm{min}$. The gap between the concentrators was typically $1 \mathrm{~mm}$. All the measurements were taken under ambient conditions.

\section{Results AND Discusions}

By using a coupled soft magnetic layer, we are able to reduce the magnetic hysteresis loss in the free layer and the MTJ junc- 


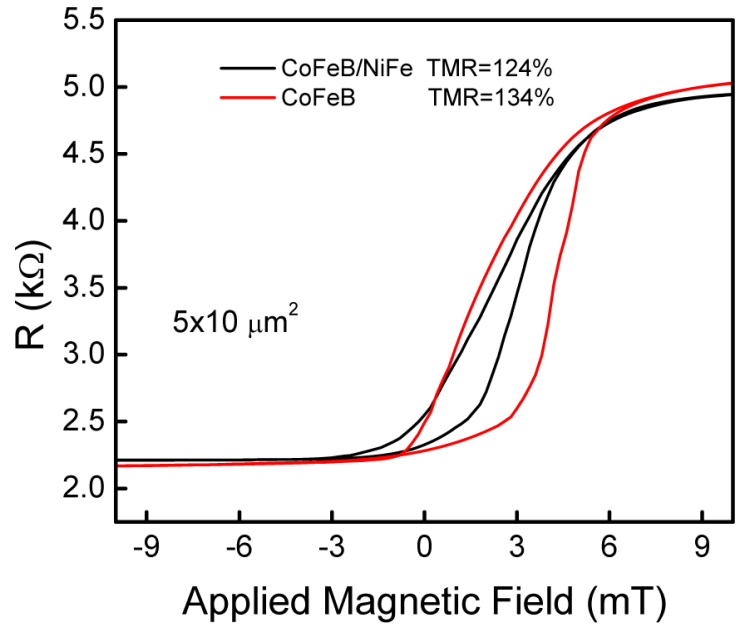

Fig. 1. MR loops of the MTJ-A with the junction area of $5 \mu \mathrm{m} \times 10 \mu \mathrm{m}$, which have the same pinned layer structures. (a) Dashed line represents that the MTJ-A has $4 \mathrm{~nm} \mathrm{Co} 20 \mathrm{Fe}_{60} \mathrm{~B}_{20}$ as a free layer. (b) Solid line represents that the MTJ-A has $4 \mathrm{~nm} \mathrm{Co}_{20} \mathrm{Fe}_{60} \mathrm{~B}_{20}$ and additional $3.3 \mathrm{~nm} \mathrm{Ni}_{80} \mathrm{Fe}_{20}$ as a free layer.

tions could have a better reversibility and linearity around zeromagnetic field, as well as smaller coercivity [15]. We prepare two different free-layer structures from the MTJ-A wafer. First, we remove the $7 \mathrm{~nm} \mathrm{Ru} / 10 \mathrm{~nm}$ Ta layers by argon milling on the half of the wafer and then deposited $3.3 \mathrm{~nm} \mathrm{Ni}_{80} \mathrm{Fe}_{20} / 10 \mathrm{~nm}$ $\mathrm{Ta} / 7 \mathrm{~nm} \mathrm{Ru}$ on it. So, all the MTJ junctions are made from the same wafer (i.e., MTJ-A wafer).

The MR loops with or without additional $\mathrm{Ni}_{80} \mathrm{Fe}_{20}$ as a free layer are shown in Fig. 1. The tunneling magneto resistance (TMR) drops from $132 \%$ to $115 \%$, which may be due to the reduction of the thickness of $\mathrm{Co}_{20} \mathrm{Fe}_{60} \mathrm{~B}_{20}$ free layer duing the milling process. The magnetic hysteresis loss in the free layer is reduced by about $42 \%$ of the coercivity that is from 4.26 to $2.46 \mathrm{mT}$. However, the MTJ-A wafer (both samples with or without $\mathrm{Ni}_{80} \mathrm{Fe}_{20}$ ) has a large exchange bias, which is not desired for sensor applications. We would prefer to design a magnetic sensor without using an external magnetic bias.

From the aforementioned results, we prepared the MTJ-B that reduced the thickness of $\mathrm{Co}_{20} \mathrm{Fe}_{60} \mathrm{~B}_{20}$ to $1.5 \mathrm{~nm}$ and additional $3.3 \mathrm{~nm} \mathrm{Ni}{ }_{80} \mathrm{Fe}_{20}$ as a free layer. We anneal these samples using similar to that of the MTJ-A, that is to anneal the samples at $350{ }^{\circ} \mathrm{C}$ under $1 \mathrm{~T}$ magnetic field along the direction of short axis of the ellipse. These samples have smaller exchange bias, as well as lower coercive force than that of MTJ-A. However, the TMR ratio of these samples is only about $45 \%$. This may relate to the fact that the crystal orientation of the $\mathrm{Co}_{20} \mathrm{Fe}_{60} \mathrm{~B}_{20}$ layer is influenced by the crystal orientation of the $\mathrm{Ni}_{80} \mathrm{Fe}_{20}$ layer. The slope of the TMR loop at the zero-magnetic field is small. In order to improve the slope at the zero-magnetic field, the second annealing process was introduced in Fig. 2. The samples were heated to $350{ }^{\circ} \mathrm{C}$ under $0.1 \mathrm{~T}$ magnetic field that is along the long axis of the ellipse. The second annealing process helps the magnetization in free layer keep as a magnetic dipole, which could rotate smoothly with decreasing the magnetic field. The slope of the TMR loop at zero-magnetic field (red line in Fig. 2) is increased by about eight times, the sensitivity changes from $0.744 \% / \mathrm{mT}$ to $5.89 \% / \mathrm{mT}$. However, the second annealing

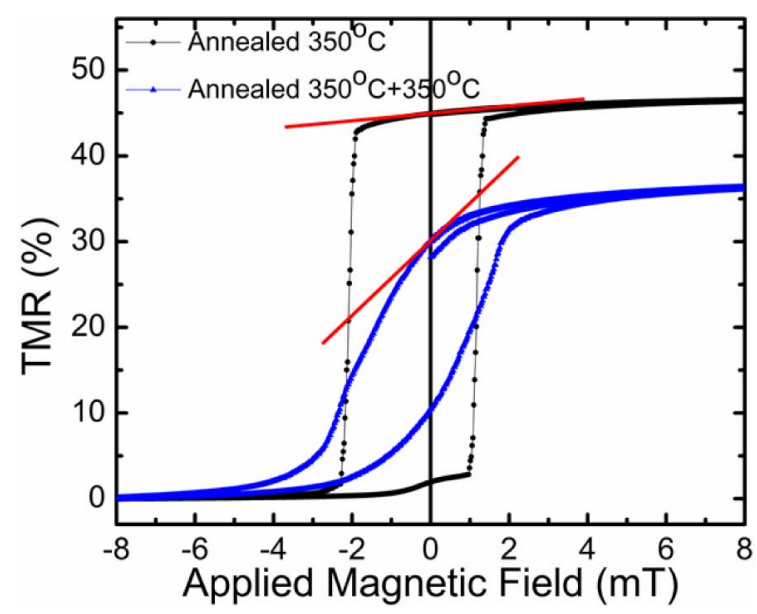

Fig. 2. TMR ratio versus applied magnetic field with different annealing treatments. (a) Loops with dots are the samples that annealed at $350{ }^{\circ} \mathrm{C}$ under $1 \mathrm{~T}$ magnetic field in the direction along the short axis of the ellipse. (b) TMR loops with triangle dots are the samples that annealed at $350{ }^{\circ} \mathrm{C}$ under $1 \mathrm{~T}$ magnetic field along the short axis and, then, annealed at $350{ }^{\circ} \mathrm{C}$ under $0.1 \mathrm{~T}$ along the long axis of the ellipse. The slopes of the TMR loops at zero-magnetic field were marked in red lines to illustrate the changing sensitivity by the annealing.

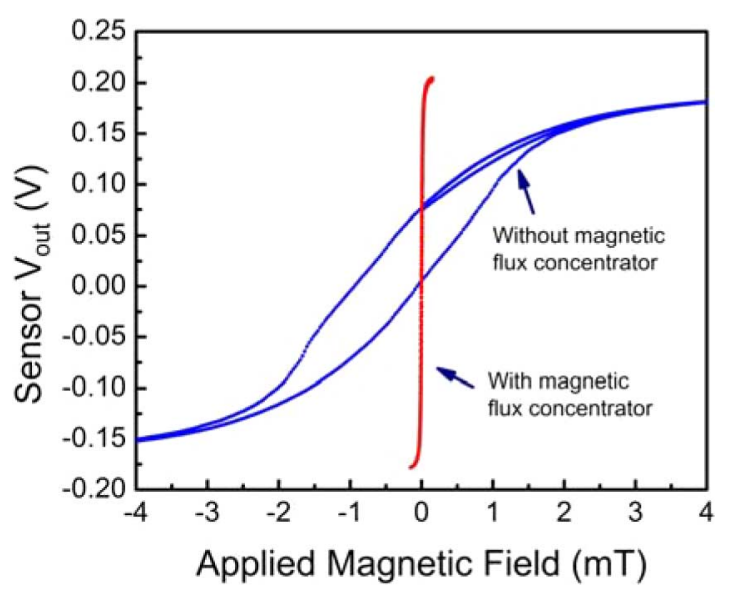

Fig. 3. Sensor output voltage (under applied voltage of $1 \mathrm{~V}$ ) versus field curve of the MTJ sensor with or without MFCs. It demonstrates that the signal of an MTJ bridge with MFCs increases by a factor of 77 .

process reduces the TMR ratio to about $35 \%$ because the magnetization of the pinned layer is also aligned toward the long axis of the ellipse.

We have made a magnetic sensor with an asymmetric bridge (formed by taking two dies and rotating them so that the pinned directions were opposite to each other). The sensor voltage output with $1 \mathrm{~V}$ bias is shown in Fig. 3. There is quite large magnetic hysteresis in the sensor without MFC in the magnetic field range of $\pm 3 \mathrm{mT}$. The sensing field range is reduced and the sensitivity is increased in the sensor with MFC. The signal of the magnetic sensor bridge with MFCs increases by a factor of 77. The magnetic hysteresis of the sensor reduced also by a factor of 77. In Fig. 4, we show that the sensitivity of this magnetic sensor as high as $750 \% / \mathrm{mT}$ has been achieved. The magnetic sensor was operated under the applied voltage of $1 \mathrm{~V}$. The output voltage of the magnetic sensor response to increasing and decreasing dc magnetic field is quite linear in the field range of $\pm 125 \mathrm{nT}$. 


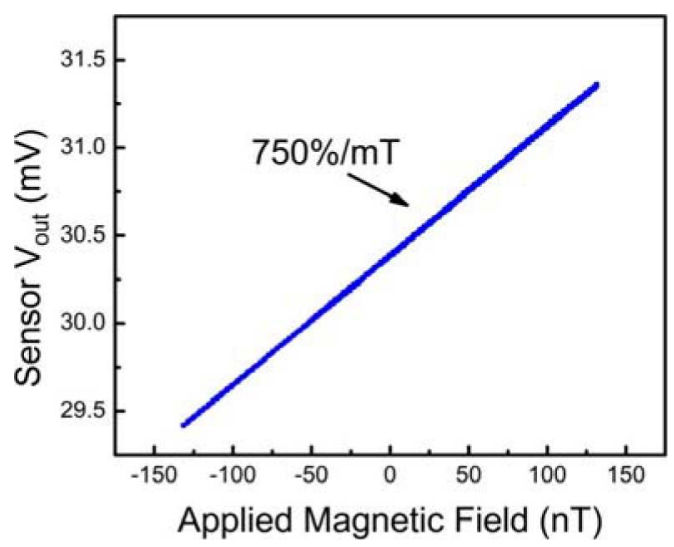

Fig. 4. Output voltage of the magnetic sensor response to increasing and decreasing dc magnetic field range of $\pm 125 \mathrm{nT}$. The magnetic sensor was operated under the applied voltage of $1 \mathrm{~V}$. The sensitivity of this sensor is $750 \% / \mathrm{mT}$.

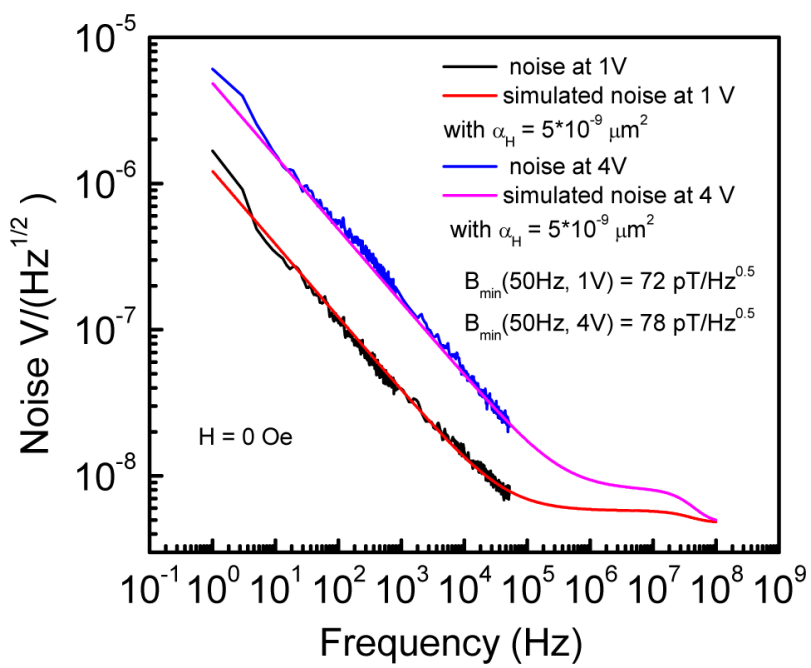

Fig. 5. Noise versus frequency of the MTJ junction of $30 \mu \mathrm{m} \times 30 \mu \mathrm{m}$ measured under the applied voltage at 1 and $4 \mathrm{~V}$ at zero-magnetic fields.

We measured the noise of the MTJ bridge in the frequency range from 1 to $5 \times 10^{4} \mathrm{~Hz}$ with $0 \mathrm{~T}$ biasing fields and under the applied voltages of 1 and $4 \mathrm{~V}$, as shown in Fig. 5. The magnetic field noise was calculated by dividing the voltage noise spectrum measured at the bridge outputs by the bridge sensitivity $d V / d B$ taken from Fig. 4 . At an applied voltage of $1 \mathrm{~V}$ across the bridge and zero applied magnetic field, the sensitivity is $7500 \mathrm{~V} / \mathrm{T}$. The noise level at $1 \mathrm{~Hz}$ is $1 \times 10^{-6} \mathrm{~V} / \mathrm{Hz}^{1 / 2}$ giving a field noise of $1 \times 10^{-6} \mathrm{~V} / \mathrm{Hz}^{1 / 2} / 7500 \mathrm{~V} / \mathrm{T}=133 \mathrm{pT} / \mathrm{Hz}^{1 / 2}$. At $1 \mathrm{kHz}$, the noise level is $2 \times 10^{-8} \mathrm{~V} / \mathrm{Hz}^{1 / 2}$, and the field noise is $2.6 \mathrm{pT} / \mathrm{Hz}^{1 / 2}$.

The noise spectrum was fitted with the calculated thermal noise for the measured value of resistance. Hooge-like parameter is about $5 \times 10^{-9} \mu \mathrm{m}^{2}$, which is about the same order of magnitude as that reported by Stearrett et al. [16].

Fig. 6 shows a real-time magnetic response curve of the magnetic sensor that was measured under an ac variation of magnetic field at $1 \mathrm{~Hz}$ and amplitude of $250 \mathrm{pT}$. The applied voltage on the sensor bridge is at $1 \mathrm{~V}$ and under ambient condition. The magnetic sensor was placed inside a coil and the signal was collected with a low-noise amplifier (gain was set at 100) and an $\mathrm{A} / \mathrm{D}$ convertor. The magnitude of the sensor voltage output is

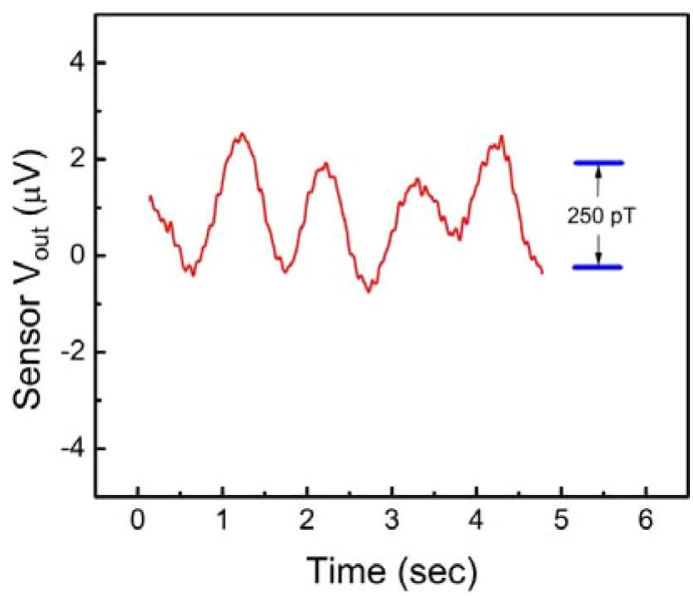

Fig. 6. Magnetic response curve: magnetic sensor output versus time under a variation of magnetic field at $1 \mathrm{~Hz}$ and amplitude of $250 \mathrm{pT}$.

about $2 \mu \mathrm{V}$. It is not a perfect sinusoid curve. The distortion may due to the thermal fluctuation of the magnetic domain in the free layer of the magnetic sensor. However, one can see that the peak-to-peak output voltage is much higher than the noise level of about $100 \mathrm{pT}$.

\section{SUMMARY}

We show a method that uses multilayer thin films to improve the performance of the soft ferromagnetic layer in MR sensor applications, by reducing the coercivity and/or improving the reversibility.

We present a simple low-power, magnetic sensor system that combines a 64-element MTJ bridge and a set of low-noise MFCs. This sensor has a sensitivity as high as $750 \% / \mathrm{mT}$. The magnetic sensor only dissipates $1 \mathrm{~mW}$ of power while operating under an applied voltage of $1 \mathrm{~V}$.

\section{ACKNOWLEDGMENT}

This work was supported by the Department of Defense (Army Research Office) under Awards W911NF-08-1-01311, W911NF-09-2-0039, and W911NF-10-2-0099, by the National Science Foundation MRSEC under Grant DMR-0820521, and by the Strategic Environmental Research and Development Program (SERDP) under Grant MM-1716.

\section{REFERENCES}

[1] W. F. Egelhoff, Jr., V. E. Höink, J. W. Lau, W. F. Shen, B. D. Schrag, and G. Xiao, "Magnetic tunnel junctions with large tunneling magnetoresistance and small saturation fields," J. Appl. Phys., vol. 107, p. 09C705, 2010.

[2] J. M. Almeida, P. Wisniowski, and P. P. Freitas, "Field detection in single and double barrier $\mathrm{MgO}$ magnetic tunnel junction sensors," $J$. Appl. Phys., vol. 103, p. 07E922, 2008.

[3] P. P. Freitas, R. Ferreira, S. Cardoso, and F. Cardoso, "Magnetoresistive sensors," J. Phys., Condens. Matter, vol. 19, p. 165221, 2007.

[4] X. Liu, D. Mazumdar, W. Shen, B. D. Schrag, and G. Xiao, "Thermal stability of magnetic tunneling junctions with $\mathrm{MgO}$ barriers for high temperature spintronics," Appl. Phys. Lett., vol. 89, p. 023504, 2006.

[5] J. Scola, H. Polovy, C. Fermon, M. Pannetier-Lecoeur, G. Feng, K. Fahy, and J. M. D. Coey, "Noise in MgO barrier magnetic tunnel junctions with $\mathrm{CoFeB}$ electrodes: Influence of annealing temperature," Appl. Phys. Lett., vol. 90, p. 252501, 2007.

[6] R. C. Chaves, P. P. F. Ocker, and W. Maass, "Low frequency picotesla field detection using hybrid $\mathrm{MgO}$ based tunnel sensors," Appl. Phys. Lett., vol. 91, p. 102504-0, 2007. 
[7] P. W. T. Pong, B. Schrag, A. J. Shapiro, R. D. McMichael, and W. F. Egelhoff, Jr., "Hysteresis loop collapse for linear response in magnetictunnel-junction sensors," J. Appl. Phys., vol. 105, p. 07E723, 2009.

[8] N. A. Stutzke, S. E. Russek, D. P. Pappas, and M. Tondra, "Low-frequency noise measurements on commercial magnetoresistive magnetic field sensors," J. Appl. Phys., vol. 97, p. 10Q107, 2005.

[9] S. H. Liou, R. Zhang, S. E. Russek, L. Yuan, S. T. Halloran, and D. P. Pappas, "Dependence of noise in magnetic tunnel junction sensors on annealing field and temperature," J. Appl. Phys., vol. 103, p. 07E920, 2008.

[10] S. Ikeda, J. Hayakawa, Y. Ashizawa, Y. M. Lee, K. Miura, H. Hasegawa, M. Tsunoda, F. Matsukura, and H. Ohno, "Tunnel magnetoresistance of $604 \%$ at $300 \mathrm{~K}$ by suppression of Ta diffusion in $\mathrm{CoFeB} / \mathrm{MgO} / \mathrm{CoFeB}$ pseudo-spin-valves annealed at high temperature," Appl. Phys. Lett., vol. 93, p. 082508, 2008.

[11] P. M. Drljača, F. Vincent, P.-A. Besse, and R. S. Popović, "Design of planar magnetic concentrators for high sensitivity hall devices," Sens. Actuators A, vol. 97-98, pp. 10-14, 2002.
[12] F. G. Aliev, R. Guerrero, D. Herranz, R. Villar, F. Greullet, C. Tiusan, and M. Hehn, "Very low $1 / f$ noise at room temperature in fully epitaxial $\mathrm{Fe} / \mathrm{MgO} / \mathrm{Fe}$ magnetic tunnel junctions," Appl. Phys. Lett., vol. 91, p. 232504-0, 2007.

[13] M. Tondra, J. M. Daughton, D. Wang, R. S. Beech, A. Fink, and J. A. Taylor, "Picotesla field sensor design using spin-dependent tunneling devices," Appl. Phys. Lett., vol. 83, p. 6688, 1998.

[14] S. H. Liou, D. Sellmyer, S. E. Russek, R. Heindl, F. C. S. Da Silva, J. Moreland, D. P. Pappas, L. Yuan, and J. Shen, "Magnetic noise in a low-power picotesla magnetoresistive sensor," Proc. IEEE 8th Ann. Conf. Sens., p. 1848, 2009.

[15] R. Zhang, R. Skomski, X. Yin, S. H. Liou, and D. Sellmyer, "Reversibility and coercivity of $\mathrm{Fe}$-alloy-Fe: $\mathrm{SiO}_{2}$ multilayers," J. Appl. Phys., vol. 107, p. 09E710-0, 2010.

[16] R. Stearrett, W. G. Wang, L. R. Shah, A. Gokce, J. Q. Xiao, and E. R. Nowak, "Evolution of barrier-resistance noise in $\mathrm{CoFeB} / \mathrm{MgO} / \mathrm{CoFeB}$ tunnel junctions during annealing," J. Appl. Phys., vol. 107, p. 064502, 2010. 